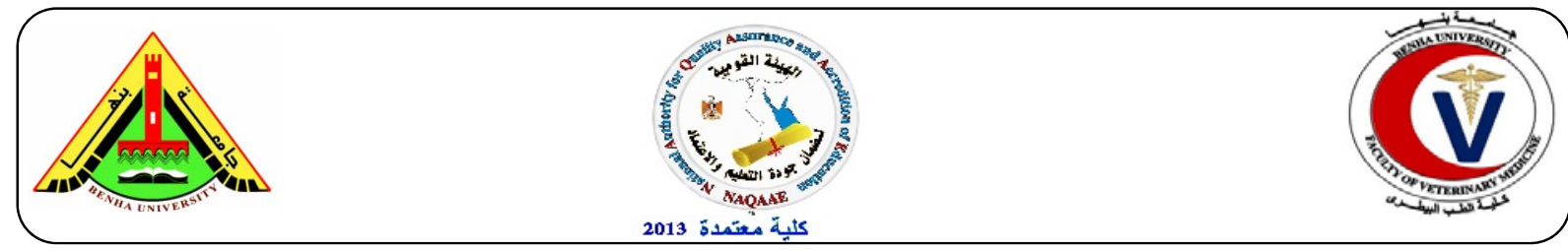

\title{
Protective role of new nanocomposite natural product (basic nano-curcumin) against breast carcinoma
}

\author{
Omayma A.R. Abou Zaid ${ }^{1}$, Fatma A. Ahmed ${ }^{2}$, Abdel Fatah M. Badwi ${ }^{3}$, Naglaa M.H. Ibrahim² \\ ${ }^{1}$ Clinical Biochemistry Department - Faculty of Veterinary Medicine- Benha University. \\ ${ }^{2}$ Medical and Aromatic Plants Department- Desert Research Center. \\ ${ }^{3}$ Applied Chemistry Department- Egyptian Petroleum Research Institute.
}

\begin{abstract}
A B S T R A C T
Present study focused on evaluation of the effect of national nancomposite product on serum biochemical profile and programmed cell death (apoptosis) by using Annexin V-FITC and PI test of breast carcinoma female rats. Basic nanocurcumin was tested for its protective effect on breast cancer female rats $(n=30)$ divided in two main groups $($ NTBR) and (TBR) which in turn classified into (TBR- Control Positive and TBR- basic nano- curcumin protective groups). Basic nano-curcumin was formulated and tested for both $\mathrm{IC}_{50}\left(\mathrm{IC}_{50}=1.0 \mu \mathrm{g}\right)$ and $\mathrm{LD}_{5 \mathrm{o}}(35 \mathrm{mg} / \mathrm{kg}$ by wt.) by using in vitro and in vivo techniques, respectively. Breast cells apoptosis was determined by Annexin V-FITC, which is a fluorescent probe binds to phosphotidylserine (PS) in a $\mathrm{Ca}^{2+}$ dependent pathway. Breast Cells were stained with Annexin V and PI. The apoptotic cells [Annexin (+) and PI (-)] were differentiated from necrotic cells [Annexin (-) and PI (+)] using flow cytometry technique. The anti-proliferative effect of basic nano-curcumin appeared much earlier due to its nano form. Also, Liver [ALT (40U/l), AST (85 U/l)] and kidney [BUN (19 mg/dl), Creatinine $(0.5 \mathrm{mg} / \mathrm{dl})$ ] functions were decreased within normal ranges.
\end{abstract}

keyword: Basic nano-curcumin, Annexin, BUN, Creatinine, AST, ALT.

(http://www.bvmj.bu.edu.eg)

(BVMJ-33(2): 107-116, DECEMBER, 2017)

\section{INTRODUCTION}

The incidence breast cancer is increasing in all regions of the world with majority of rise especially in developing countries (Globocan, 2008). In Egypt, breast cancer is the most common cancer among women and is estimated to be the cause of $(22 \%)$ all cancer-related female deaths. Prognosis and survival rates for breast cancer vary greatly depending on the cancer type, stage, treatment, and geographical location of the patient. (World Center Report, 2014). Chemoprevention is a promising anti-cancer approach with reduced secondary effects in comparison to classical chemotherapy. Most chemopreventive agents known until today are plant extracts. Curcuma longa $\mathrm{L}$ or turmeric is a tropical plant native to southern and southeastern tropical Asia. A perennial herb belonging to the ginger family, the parts used are the rhizomes (Aggarwal et al., 2007). Perhaps the most active component in turmeric is curcumin, which may make up 2 to $5 \%$ of the total spice in turmeric. Curcumin is a diferuloylmethane present in extracts of the plant. Curcuminoids are responsible for the yellow color of turmeric powder. The pure orange-yellow, crystalline powder is insoluble in water (Aggarwal et al.,
2003). Curcumin, a polyphenolic compound, has emerged worldwide as a potent therapeutic substance which displays a wide range of pharmacological properties against various human disorders, such as metabolic and infectious diseases, diabetes, psoriasis, rheumatoid arthritis, atherosclerosis, Parkinson's and Alzheimer's diseases and cancer (Wilken et al., 2011). In vitro and in vivo studies have indicated that, curcumin induces chemopreventive and chemotherapeutic effects against various types of human cancers (Annelyse et al., 2005). Trials on human and mouse observed that oral consumption of curcumin shows less bioavailability due to its poor aqueous solubility and it undergoes intestinal metabolism (Sharma et al. 2005). Recently, nanoparticle-based delivery systems will probably be suitable for highly hydrophobic agents like curcumin which these obstacles of curcumin can be eliminated by synthesis of curcumin nanoparticles which can be used for the purpose of longer circulation, permeability and increased resistance to metabolic processes (Ravichandran 2013). 


\section{MATERIALS \& METHODS}

\subsection{Extraction of Curcumin from turmeric plant rhizomes}

The dried powder of turmeric $(500 \mathrm{~g})$ was placed in the collar of Soxhlet apparatus + (1000 $\mathrm{ml}$ ) of methanol as a solvent. The extraction was continued till clear solvent was seen in the collar. The extract was transfer to rotary evaporator to evaporate the solvent residue. The percentage yield of the extract was calculated using the following equation: Yield $(\%)=$ Initial wt. of the dried powder of turmeric / Final wt. of the dried extract $\times 100$

The extracts were kept in the refrigerator till further use.

\subsection{Preparations and Measurements of novel nano-composite (Basic Nano-Curcumin)}

To prepare curcumin nanoparticles, $1 \mathrm{M}$ curcumin with low solubility in water was mixed with $4 \mathrm{M}$ sodium bicarbonate buffer, then grinded using mechanical ball mill (350 round/Sec) for 8 hrs. TEM (Transmission electron microscope) image was taken which represented the nano- range of the novel nano-composite (Basic curcumin) from $6.87-12.7 \mathrm{~nm}$ in diameter and has spherical shape.

\subsection{IC50 Value (In vitro)}

The antitumor effect and inhibitory concentration $50 \quad\left(\mathrm{IC}_{50}\right)$ of this novel nanocomposite will be investigated against MCF-7 (breast carcinoma cell line) (Gangadevi, \& Muthumary, 2007).

\subsection{LD50 Value (In vivo)}

Acute toxicity study (Determination of $\mathrm{LD}_{50}$ ) for nano-composite was determined to (Finney, 1964).

\subsection{Experimental Animals}

Thirty Virgin Female Sprague Dawley rats, 4 weeks old, weighing 100-120 g were purchased from "The Laboratory Animals Research Center", Faculty of Veterinary Medicine, Benha University, and housed in separate wire mesh cages, exposed to good ventilation, humidity and to a $12-\mathrm{hr}$ light/dark cycle .Constant supplies of standard pellet diet, fresh and clean drinking water were supplied ad-libitum. The animals were left for 15 days for acclimatization prior to the beginning of the experiment, and kept at constant environmental and nutritional conditions throughout the period of the experiment.

\subsection{Induction of Tumor:}

MNU was dissolved immediately prior to its use in $4 \mathrm{ml}$ of $\mathrm{NaCl}(9 \%)$ and acidified to $\mathrm{pH} 4$ with acetic acid was injected intraperitoneally at the dose rate of $50 \mathrm{mg} / \mathrm{kg}$ body weight five times at 50 , 70, 80, 90 and 110 days of age (Saminathan, et al., 2014).

\subsection{Experimental Design:}

Rats were randomly divided into two main groups, placed in individual cages and classified as follow: Group (1): Non Tumor Bearing Rats (NTBR) : Comprised 10 rats, control normal group received physiological saline contain $1 \%$ tween 80 orally, provided with a constant supply of standard pellet diet and plenty of fresh, clean drinking water ad-libitum. Group (2): Tumor Bearing Rats (TBR): Comprised 20 rats, induced mammary carcinogenesis group administered with MNU (I.P) for induction of mammary cancer at a dose level of (50mg/ kg.by wt.), this group was divided into two subgroups: Sub-gp-1 (TBR - Control Positive) $(n=10)$ : Considered as control mammary carcinogenesis group for comparison with nanocomposite treated group. Sub-gp-2 (NMU + Basic Nano-curcumin Protected Group) $(\mathrm{n}=10)$ : Rats were treated with basic nano curcumin at an oral dose of $(35 \mathrm{mg} / \mathrm{kg}$ by wt. day after day) dissolved in water one time per day, at the end of the second week (On the $16^{\text {th }}$ day) rats was injected intraperitoneally by (NMU) as described before, with continued doses, until the end of experiment.

\subsection{Histopathological Examination:}

Mammary specimens were taken from different parts of mammary glands of female rats, preserved in $10 \%$ buffered neutral formalin and subjected to microscopic examination according to (Banchroft and Stevens, 1996).

\subsection{Biochemical parameters}

BUN, serum creatinine, ALT and AST activities were determined according to the methods (Young, 1990 and Murray Charles, 1984) respectively.

\subsection{Annexin V FITC-PI Values}

According to (Andree, et al., 1990), the test was done on mammary tissue samples by using flow cytometer.

\subsection{Statistical analysis}

It was carried out using ANOVA test with two factors under significance level of 0.05 for the whole results using CoSTAT.

\section{RESULTS}


Figure (1): The figure shows the $\mathrm{IC}_{50}$ value (intermediate inhibitory concentration) of basic nano-curcumin $(1.0 \mu \mathrm{g})$. Figure $(2 \mathrm{a}, \mathrm{b} \& \mathrm{c})$ : The figure represents the histopathological examination for control \& nano-composite groups which represents the difference in tissues morphology (a): a photomicrograph of the (negative control) mammary gland with normal lobules embedded in dense stroma, acini, (b): a photomicrograph of the (positive control) mammary gland treated with NMU and (c): histological section of the breast cancer tissue in rats treated with Basic NanoCurcumin represents improvement in mammary tissues morphology. Table (1): The table shows the blood urea nitrogen (BUN) and creatinine values $(\mathrm{mg} / \mathrm{dL})$, which demonstrated that, through (TBR gp.) the level of blood urea nitrogen (BUN) was observed to be more than normal range (7-20 $\mathrm{mg} / \mathrm{dl})$. No significant difference pattern of blood urea nitrogen level was noted through (NTBR gp) and basic nano-curcumin treated group, which indicate normal value. On other hand, the mean value of creatinine among breast cancer group (TBR) observed to be increased than normal reference range $(0.6-0.8 \mathrm{mg} / \mathrm{dl})$. Also, no specific alterations were observed in creatinine level between the normal group (NTBR) and basic nanocurcumin treated group.

Table (1): Blood Urea Nitrogen (BUN) \& Creatinine values $(\mathrm{mg} / \mathrm{dL})$.

\begin{tabular}{ccc}
\hline Groups & BUN mg/dL & Creatinine mg/dL \\
\hline NTBR & $17^{\mathrm{d}} \pm 1.52$ & $0.3^{\mathrm{d}} \pm 0.173$ \\
TBR & $40^{\mathrm{a}} \pm 2.88$ & $1.4^{\mathrm{a}} \pm 0.014$ \\
TBR-BNC & $19^{\mathrm{d}} \pm 1.52$ & $0.5^{\mathrm{d}} \pm 1.53$ \\
\hline
\end{tabular}

BUN \& creatinine values between treated groups $(\mathrm{NTBR}=$ Non Tumor Bearing Rats, $\mathrm{TBR}=$ Tumor Bearing Rats, TBR-BNC $=$ Tumor Bearing Rats - Basic Nano-Curcumin). Mean values with different super script letters in the same rows are significantly different at $(p<0.05)$. Figure (3): The figure represents the blood urea nitrogen (BUN) and creatinine Values $(\mathrm{mg} / \mathrm{dL})$ among tested groups. The data obtained showed that, no significant difference pattern of blood urea nitrogen level was noted through (NTBR gp) and basic nano-curcumin treated group, which indicate normal value. Also, no specific alterations were observed in creatinine level between the normal group (NTBR) and basic nano-curcumin treated group. Table (2): The table illustrates the ALT and AST (U/L) values among tested groups. The data represents the mean value of Aspartate aminotransferase (AST or SGOT) level of (NTBR $\mathrm{gp)}$ was observed to be within normal reference range $(0-80 \mathrm{U} / \mathrm{L})$ as shown in (Table 4$)$. However, no significant difference in AST level was recorded between (NTBR gp) and basic nano-curcumin treated group. Similarly, the mean value of alanine aminotransferase (ALT or SGPT) level was reported to be within normal reference range $(0$ $40 \mathrm{U} / \mathrm{L}$ ) among (NTBR). However; normal level of ALT was reported among basic nano-curcumin treated group, which showed significant difference between the (TBR gp) and basic nano-brown algae treated group.

Table (2): ALT \& AST (U/L) Values among tested groups.

\begin{tabular}{ccc}
\hline Groups & ALT & AST \\
\hline NTBR & $39.6^{\mathrm{d}} \pm 2.72$ & $85^{\mathrm{d}} \pm 2.88$ \\
TBR & $187^{\mathrm{a}} \pm 5.82$ & $211.6^{\mathrm{a}} \pm 15.88$ \\
TBR-BNC & $40^{\mathrm{d}} \pm 2.88$ & $85^{\mathrm{d}} \pm 3.38$ \\
\hline
\end{tabular}

ALT \& AST values between treated groups $(\mathrm{NTBR}=$ Non Tumor Bearing Rats, $\mathrm{TBR}=$ Tumor Bearing Rats, TBR-BNC $=$ Tumor Bearing Rats - Basic NanoCurcumin). Mean values with different super script letters in the same rows are significantly different at $(p$ $<0.05)$.

Figure (4): The figure shows the AST and ALT (U/L) values among tested groups, which no significant difference in AST level was recorded between (NTBR gp) and basic nano-curcumin treated group. Likewise, normal level of ALT was reported among basic nano-curcumin treated group, which showed significant difference between the (TBR gp).

Fig. 5 (A \& B): The figure shows the apoptotic rate among tested groups using Annexin V-FITC and PI test by flow cytometry technique for apoptosis rate determination. The viable cells $(97.80 \%, 82.6 \%)$ among NTBR and protective basic nano-curcumin groups were respectively, early apoptosis $(0.13 \%)$ among protective basic nano-curcumin group, in late or final stages of apoptosis, protective basic nano-curcumin group were recorded $(3.6 \%)$ in comparison with TBR gp $(13.40 \%)$. Significant necrotic levels were observed in cells treated with protective basic nano-curcumin $(15.66 \%)$. Table (3): The table represents apoptotic rate among tested groups, which the flow cytometry study with Annexin V assay showed that $(97.80 \%, 82.6 \%)$ among NTBR and protective basic nano-curcumin groups were viable respectively, where a significant decrease in viable cells were noted $(0.13 \%)$ among protective 
basic nano-curcumin group were early apoptotic rather than TBR group. In late or final stages of apoptosis, protective basic nano-curcumin group were recorded $(3.6 \%)$ in comparison with TBR gp $(13.40 \%)$ were necrotic $(\mathrm{P}<0.05)$. No apoptosis was detected in NTBR gp in necrotic phase, however; significant necrotic levels were observed in cells treated with protective basic nanocurcumin $(15.66 \%)$.

Table (3): Apoptosis rate among tested groups.

\begin{tabular}{|c|c|c|c|c|}
\hline & LL & LR & UR & $\mathrm{UL}$ \\
\hline Groups & Viable cells\% & Early apop. \% & Late apop. \% & Necrosis $\%$ \\
\hline NTBR & $97.9^{\mathrm{a}} \pm 0.088$ & $0^{a}$ & $0^{\mathrm{e}}$ & $0^{\mathrm{b}}$ \\
\hline TBR & $65.9^{b c} \pm 2.098$ & $0.9^{\mathrm{a}} \pm 0.49$ & $13.4^{\mathrm{ab}} \pm 0.688$ & $9.7^{b} \pm 3.748$ \\
\hline TBR-BNC & $82.6^{\mathrm{ab}} \pm 5.63$ & $0.13^{\mathrm{a}} \pm 0.033$ & $3.6^{\mathrm{d}} \pm 0.185$ & $15.66^{\mathrm{ab}} \pm 5.14$ \\
\hline
\end{tabular}

$\mathrm{NTBR}=$ Non Tumor Bearing Rats, TBR $=$ Tumor Bearing Rats, TBR-BNC $=$ Tumor Bearing Rats - Basic NanoCurcumin). Mean values with different super script letters in the same rows are significantly different at $(p<0.05)$.

Fig. (1): $\mathrm{IC}_{50}$ value of basic nano-curcumin.

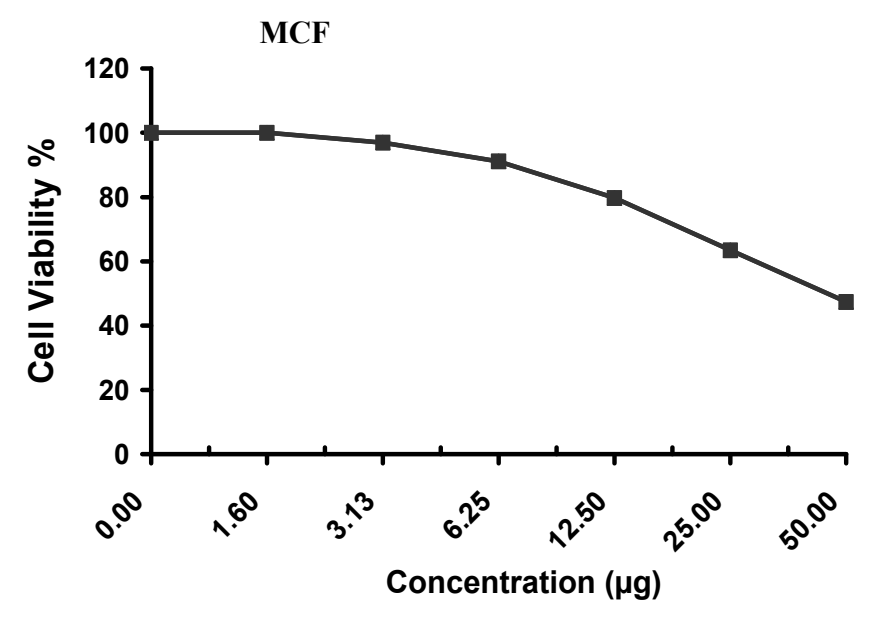

Figure 2 ( $\mathrm{a}, \mathrm{b} \& \mathrm{c})$ : Histopathological examination for control \& nano-composite groups.

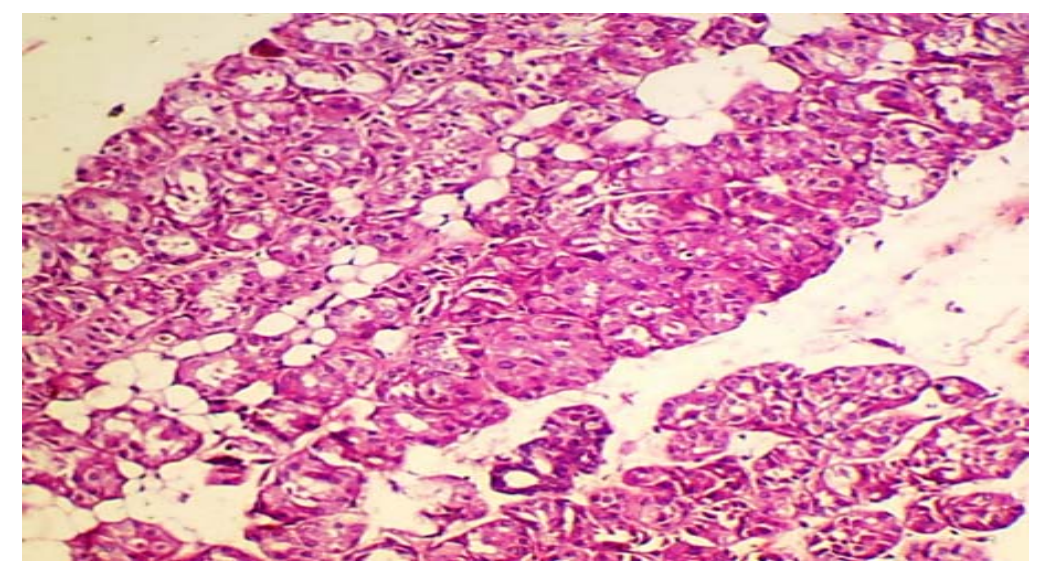


Fig. 2(a): normal breast tissues (NTBR-gp)

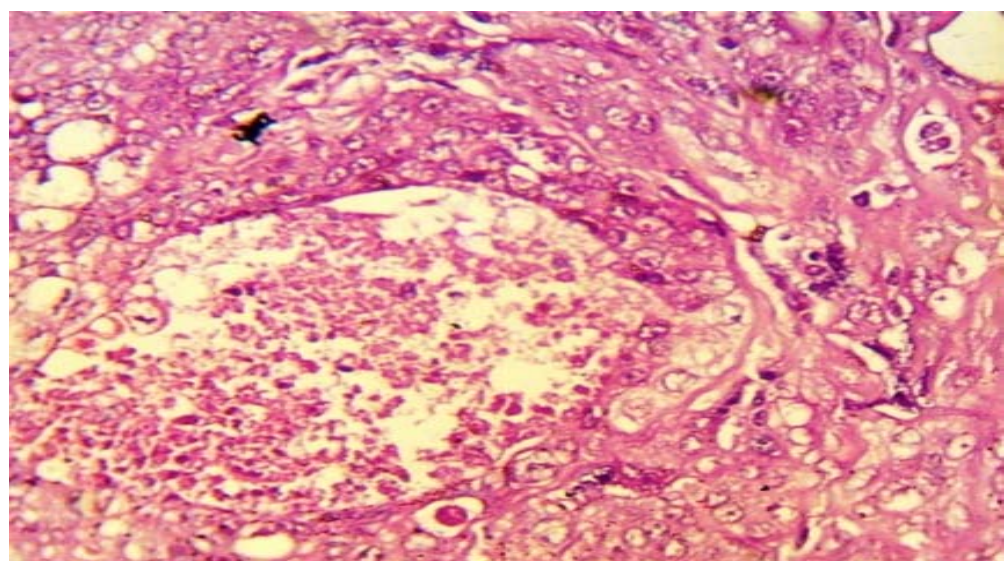

Fig. 2(b): breast carcinoma tissues (TBR-gp)

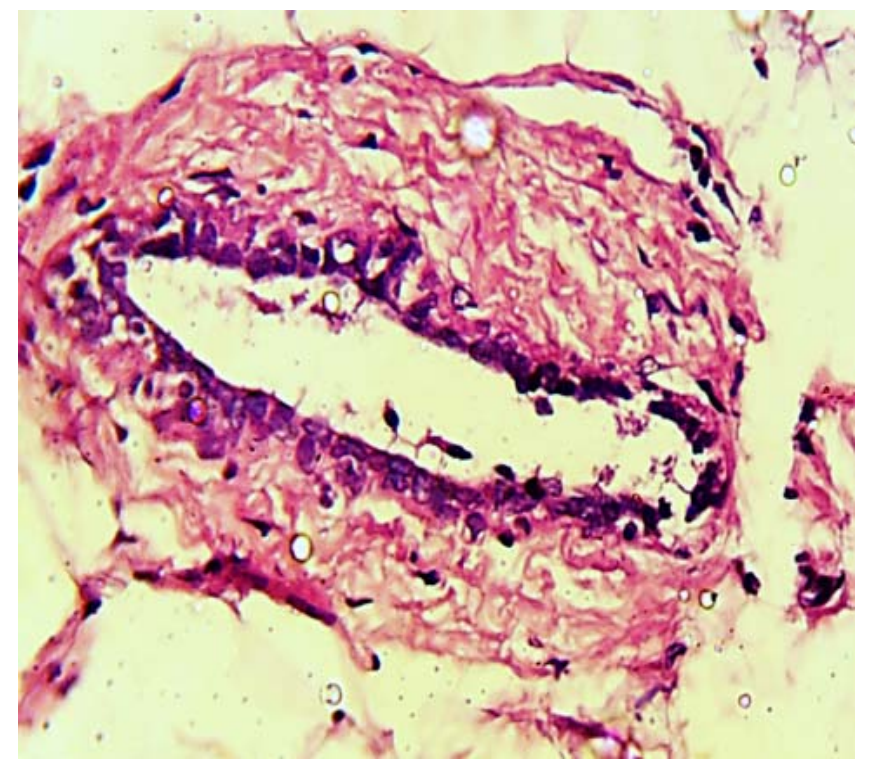

Fig.2(c): breast carcinoma tissues treated with basic nano-cutcumin

Table (1): Blood Urea Nitrogen (BUN) \& Creatinine values (mg/dL).

\begin{tabular}{ccc}
\hline Groups & BUN mg/dL & Creatinine mg/dL \\
\hline NTBR & $17^{\mathrm{d}} \pm 1.52$ & $0.3^{\mathrm{d}} \pm 0.173$ \\
TBR & $40^{\mathrm{a}} \pm 2.88$ & $1.4^{\mathrm{a}} \pm 0.014$ \\
TBR-BNC & $19^{\mathrm{d}} \pm 1.52$ & $0.5^{\mathrm{d}} \pm 1.53$ \\
\hline
\end{tabular}

BUN \& creatinine values between treated groups $(\mathrm{NTBR}=$ Non Tumor Bearing Rats, TBR= Tumor Bearing Rats, TBR$\mathrm{BNC}=$ Tumor Bearing Rats - Basic Nano-Curcumin). Mean values with different super script letters in the same rows are significantly different at $(p<0.05)$. 
Figure (3): Blood urea nitrogen (BUN) \& creatinine values (mg/dL) among tested groups.

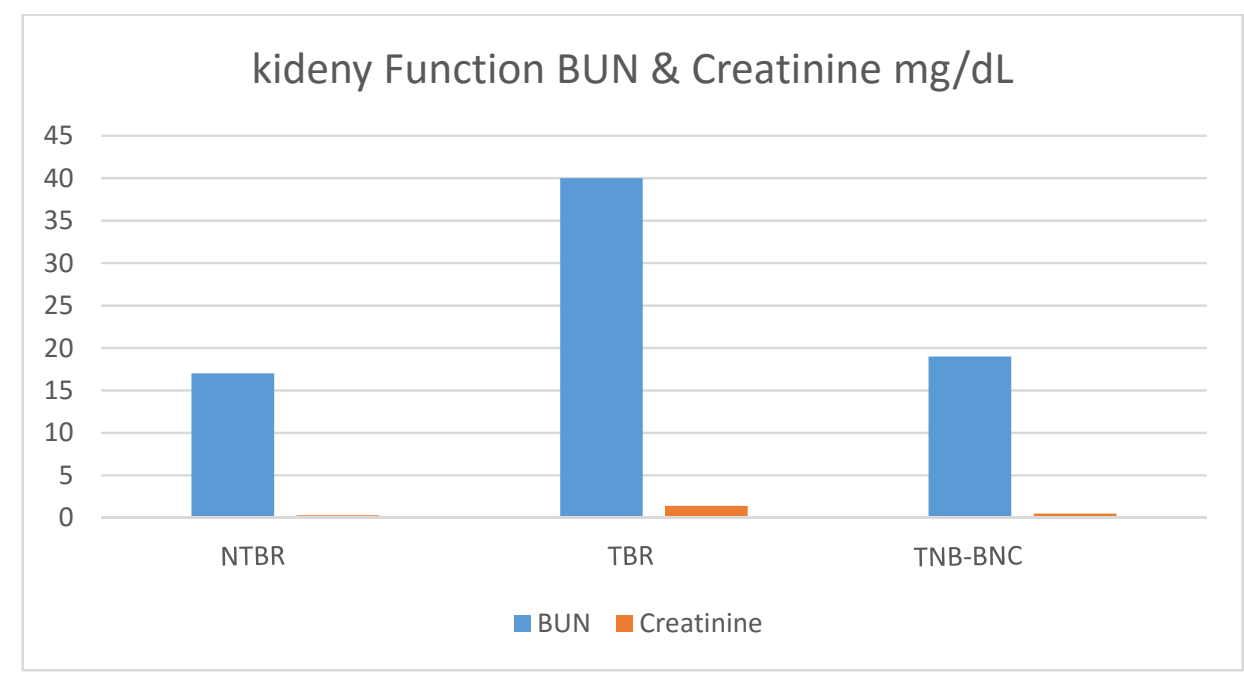

$(\mathrm{NTBR}=$ Non Tumor Bearing Rats, $\mathrm{TBR}=$ Tumor Bearing Rats, TBR-BNC $=$ Tumor Bearing Rats - Basic NanoCurcumin).

Table (2): ALT \& AST (U/L) Values among tested groups.

\begin{tabular}{ccc}
\hline Groups & ALT & AST \\
\hline NTBR & $39.6^{\mathrm{d}} \pm 2.72$ & $85^{\mathrm{d}} \pm 2.88$ \\
TBR & $187^{\mathrm{a}} \pm 5.82$ & $211.6^{\mathrm{a}} \pm 15.88$ \\
TBR-BNC & $40^{\mathrm{d}} \pm 2.88$ & $85^{\mathrm{d}} \pm 3.38$ \\
\hline
\end{tabular}

Figure (4): AST \& ALT (U/L) Values among tested groups.

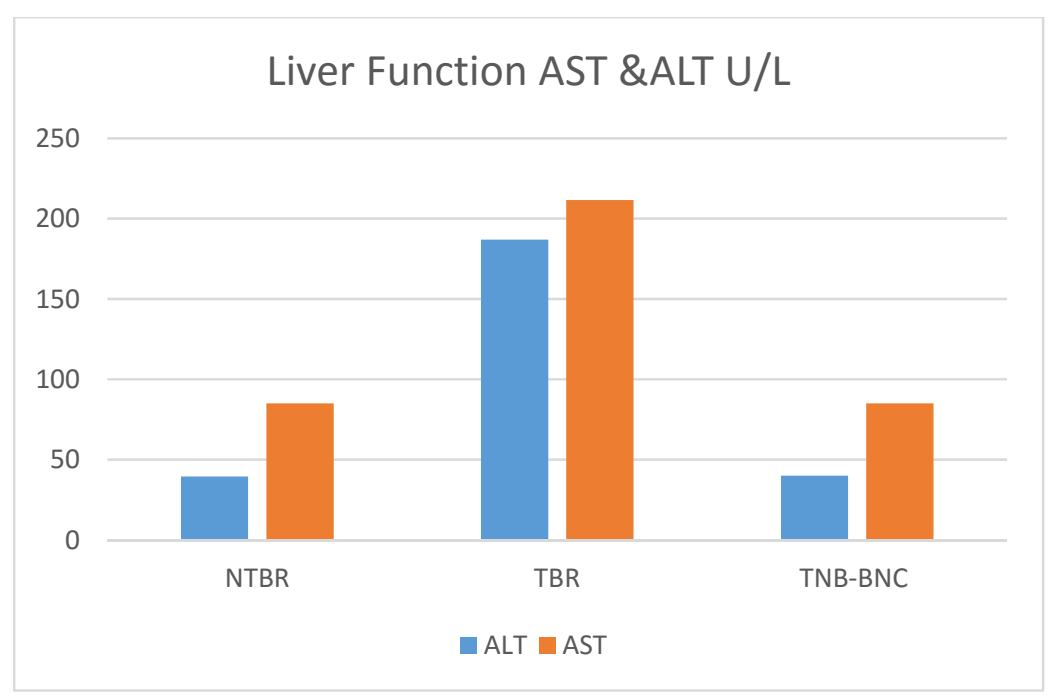

$(\mathrm{NTBR}=$ Non Tumor Bearing Rats, $\mathrm{TBR}=$ Tumor Bearing Rats, TBR-BNC $=$ Tumor Bearing Rats - Basic NanoCurcumin) 
Fig. 5 (A \& B): Apoptosis rate among tested groups.

(A)

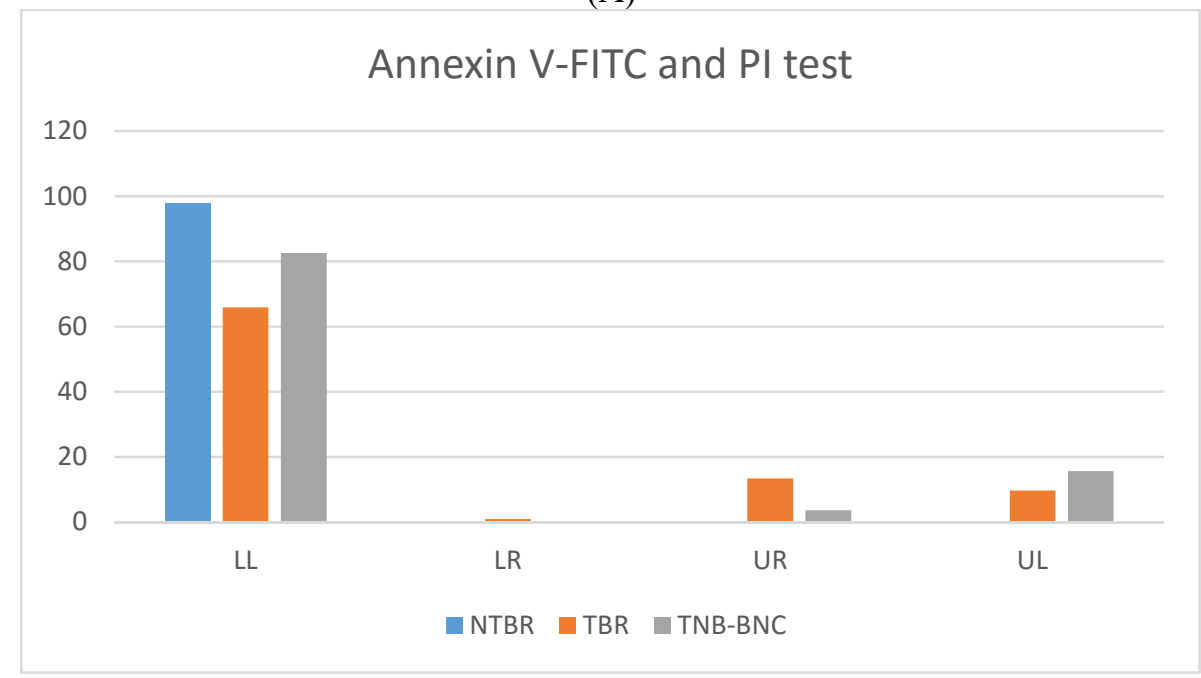

(B)
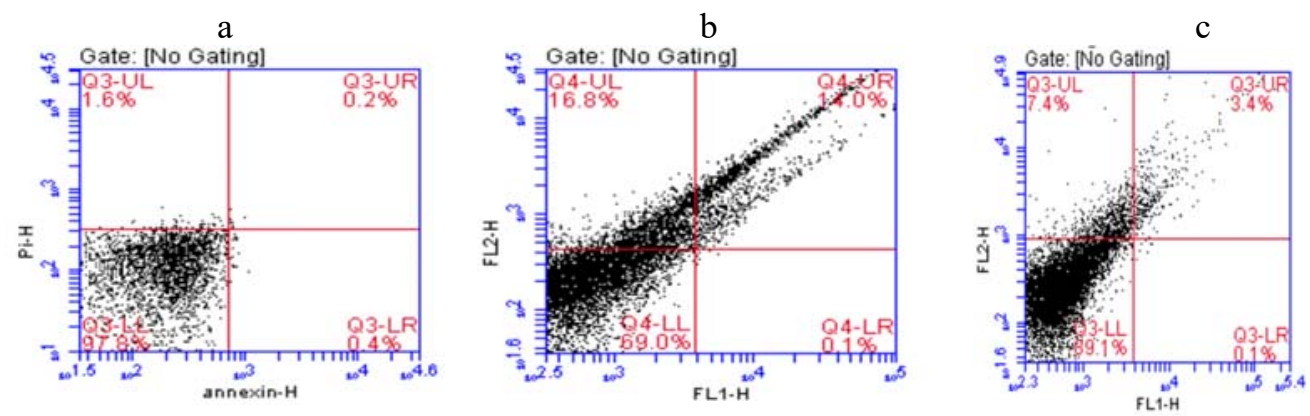

Annexin V-FITC and PI test by flow cytometry technique for apoptosis rate determination (a): NTBR gp, (b): TBR gp \& (c): protective Basic Nano-Curcumin gp, which $\mathrm{LL}=$ viable cells, $\mathrm{LR}=$ early apoptosis, $\mathrm{UR}=$ late apoptosis and $\mathrm{UL}=$ necrosis. $(\mathrm{NTBR}=$ Non Tumor Bearing Rats, $\mathrm{TBR}=$ Tumor Bearing Rats, TBR-BNC= Tumor Bearing Rats - Basic NanoCurcumin).

Table (3): Apoptosis rate among tested groups.

\begin{tabular}{ccccc}
\hline & LL & LR & UR & UL \\
Groups & Viable cells\% & Early apop. \% & Late apop. \% & Necrosis\% \\
\hline NTBR & $97.9^{\mathrm{a}} \pm 0.088$ & $0^{\mathrm{a}}$ & $0^{\mathrm{e}}$ & $0^{\mathrm{b}}$ \\
TBR & $65.9^{\mathrm{bc}} \pm 2.098$ & $0.9^{\mathrm{a}} \pm 0.49$ & $13.4^{\mathrm{ab}} \pm 0.688$ & $9.7^{\mathrm{b}} \pm 3.748$ \\
TBR-BNC & $82.6^{\mathrm{ab}} \pm 5.63$ & $0.13^{\mathrm{a}} \pm 0.033$ & $3.6^{\mathrm{d}} \pm 0.185$ & $15.66^{\mathrm{ab}} \pm 5.14$ \\
\hline
\end{tabular}

Annexin V-FITC and PI test by flow cytometry technique for apoptosis rate determination. NTBR $=$ Non Tumor Bearing Rats, $\mathrm{TBR}=$ Tumor Bearing Rats, TBR-BNC $=$ Tumor Bearing Rats - Basic Nano-Curcumin). Mean values with different super script letters in the same rows are significantly different at $(p<0.05)$.

\section{DISCUSSIONS}

The antitumor effect and inhibitory concentration $50 \quad\left(\mathrm{IC}_{50}\right)$ of the novel nano- composite (basic nano-curcumin) was investigated against MCF-7 (breast carcinoma cell line), which the inhibitory activity against breast carcinoma cells was detected under these experimental 
conditions with $\mathrm{IC}_{50}=1.0 \mu \mathrm{g}$. According to (Finney, 1964), the $\mathrm{LD}_{50}$ value for Nano-composite was $35 \mathrm{mg} / \mathrm{kg}$ body weight, which the half numbers of animals were died through two months after the daily administration of the appropriated dose. This result illustrated that the nano-composite had wide safety range due to the most noticeable features of curcumin is its extremely good tolerance and its very low toxicity and side effects.

Curcumin is Generally Recognized as Safe by the Food and Drug Administration (FDA) FAO and WHO Expert Committee on Food Additives (NCI, 1996). This results were explained by the histopathological examination which showed the following; in contrast to the normal mammary tissues of the negative control group (fig. 2 a), a number of alterations were observed in the morphology of breast tissues in the positive control group (fig. $2 \mathrm{~b}$ ). An increase in the number of acini, in addition to epithelial differentiation with secretory material, invasive ductal carcinoma (IDC), hyperplastic ducts containing more than three layers of epithelial cells and large dilated ducts in a lobular configuration were also noticed. There were occasional areas showing benign proliferation of the ducts and crowding of acini. Also, scattered atypical cells with hyperchromatic nuclei (an indication of early stromal invasion), in combination with DCIS was noted. This is an indication of early invasive cancerous change as described by (Pia-Foschini, et al., 2003).

However, the microscopic examination of the treated group of rat with basic nano-curcumin investigated that, moderate pathological effect, Tubular carcinoma showing bland-looking tumor cells arranged in tubules that possess widely patent lumens. Myoepithelial cells are absent, and the malignant tubules are arranged in an irregular stellate pattern. The intervening stroma is densely fibrotic (Fig. 2 c). In the present study, among tested female rats $($ no $=30)$ blood urea nitrogen (BUN) provides a rough measurement of the glomerular filtration rate. Through (TBR gp.) the level of blood urea nitrogen (BUN) was observed to be more than normal range $(7-20 \mathrm{mg} / \mathrm{dl})$, which the highly significant increase in tumor-bearing female rats in serum urea concentration was confirmed by the results observed by (Hussein and Azab, 1997), who observed that, there was a highly significant increase in plasma urea concentration in tumor bearing mice. The author accredited such increase in blood urea concentration to catabolic effect of tumor and the increase in urea production.

No significant difference pattern of blood urea nitrogen level was noted through (NTBR gp) and basic nano-curcumin treated group, which indicate normal value as shown in (Figure 3). On other hand, the mean value of creatinine among breast cancer group (TBR) observed to be increased than normal reference range $(0.6-0.8 \mathrm{mg} / \mathrm{dl})$, which the highly significant increase in serum creatinine concentration in tumor bearing rats and this agree with those reported by (Hussein, 2003), who detected a significant increase serum creatinine level in mice-bearing Ehrlich ascites carcinoma due to muscle necrosis. Also, no specific alterations were observed in creatinine level between the normal group (NTBR) and basic nanocurcumin treated group. Similar results were reported by (Yousef, et al., 2008) who showed that, treatment with curcumin alone caused a significant decrease creatinine level due to the protective effect of curcumin as seen in (Figure 3).

Besides that, the level of enzymes (aspartate aminotransferase, alanine aminotransferase) were analyzed for the proper functioning of liver. Liver function test was used to screen liver infection, to monitor disease progression and possible side effects of medication used. Indeed, the mean value of aspartate aminotransferase (AST or SGOT) level of (TBR gp) was observed to be above normal reference range $(0-80 \mathrm{U} / \mathrm{L})$ as shown in (Table 2).However, no significant difference in AST level was recorded between (NTBR gp) and basic nanocurcumin treated group. Similarly, the value of alanine aminotransferase (ALT or SGPT) level was reported to be within normal reference range (0 $40 \mathrm{U} / \mathrm{L}$ ) among (NTBR) and the value was noted to be $126.33 \mathrm{U} / \mathrm{L}$ among (TBR gp) (Table 2). However; normal level of ALT was reported among basic nano-curcumin treated group, which showed significant difference between it and the (TBR gp) as in (Figure 4).

The elevation in AST and ALT values in (TBR gp) was similar to (Rafei et al. 1993), which recorded that; a rise in plasma hepatic enzyme activities were observed in tumor bearing rats is the results of changes in the liver indicated by the incidence of tumor. The recorded increase in plasma ALT and AST activities in TBR gp of the present study might be due to comprehensive destruction of liver cells and release of liver enzymes into plasma after tumor induction. Therefore, from previous statistical results; treatment by basic nano-curcumin as a prevention trend improves serum chemical blood profile in breast carcinoma female rats.

Apoptosis, or programed cell death, can result in a selective advantage for a damaged cell. For that, measuring apoptosis using flow cytometry is 
one of the most common assays, it may be because of the many different ways to determine if specific cellular subsets are sensitive to a given drug or treatment. Apoptosis was studied by flow cytometry and Annexin V-FITC, and evaluated by using propidium iodide assays (Vermes, et al., 1995).

Basic nano-curcumin significantly enhanced the decrease in $\mathrm{IC}_{50}$ rate, and the treated cells evidenced apoptosis. This could be explained by which cells internalize phosphatidylserine (PS), a lipid found on the inner surface of the cell membrane that can be branded with fluorochromeconjugated annexin $\mathrm{V}$. It is therefore possible to make a distinction between viable cells (LL) (stained negative for both annexin V-FITC and propidium iodide [PI]), early apoptosis (LR) (stained positive for annexin V-FITC and negative for PI), late apoptosis or cell death (UR) (stained positive for both annexin V-FITC and PI), and necrosis (LL) (stained positive for PI) (Fig. 5 a \& b) as showed by (Ravi, et al., 2011).

In this study, the flow cytometry study with Annexin V assay showed that, $(97.80 \%, 82.6 \%)$ among NTBR and protective basic nano-curcumin groups were viable, respectively, where a significant decrease in viable cells were noted $(0.13 \%)$ among protective basic nano-curcumin group were early apoptotic rather than TBR group. In late or final stages of apoptosis, protective basic nano-curcumin group were recorded $(3.6 \%)$ in comparison with TBR gp (13.40\%) were necrotic $(\mathrm{P}<0.05)$ (Figure 5). No apoptosis was detected in NTBR gp in necrotic phase.

However; significant necrotic levels were observed in cells treated with protective basic nano-curcumin (15.66\%) (Table 3). It has also been reported that, basic nano-curcumin acts at molecular level by damaging mitosis and inducing cell-cycle arrest as confirmed by (Ramachandran, et al., 2002). On the other hand, the chemopreventive effect of basic nano-curcumin on breast cancer cells is improved by its nano-form; this tactic has the prospective to overcome some major limitations of chemotherapy and may be a promising strategy for future applications in breast cancer therapy.

\section{CONCLOSION}

Present study focused on evaluation of serum biochemical profile and programmed cell death (apoptosis) by using Annexin V-FITC and PI test of breast carcinoma female rats. Results was indicated normal levels of biochemical components of blood among basic nano-curcumin gp and hence protecting organs system. Normal level of AST, ALT enzymes, blood urea nitrogen and creatinine directly indicate the improvement of functioning of liver and kidney. Although, results obtained from Annexin V-FITC and PI test concluded that, the anti-proliferative effect of basic nano-curcumin appeared much earlier when the drug was in nanoparticles formula, the treated cells evidenced apoptosis. This approach has of basic nano-curcumin may be a promising strategy for future applications in breast cancer therapy, which confirmed by histological results.

\section{REFERENCES}

Aggarwal, B.B.; Kumar, A. and Bharti, A.C. (2003). Anticancer potential of curcumin: preclinical and clinical studies. Anticancer Res., 23: 363-398.

Aggarwal, B.B.; Sundaram, C.; Malani, N. and Ichikawa, H. (2007). Curcumin: the Indian solid gold. Med Biol., 595:1-75.

Andree, H.A.; Reutelingsperger, CP.; Hauptmann, R.; Hemker, H.C.; Hermens, W.T. and Willems, G.M. (1990). Binding of vascular anticoagulant alpha (VAC alpha) to planar phospholipid bilayers. J Biol Chem., 265: 4923-8.

Annelyse, D.; Romain, B.; Sylvie, D.; Michael, S.; Franck, M.; Estelle, H.; Mario. and Dicato, M.D. (2005). Chemopreventive and therapeutic effects of curcumin. Cancer Letters, 223: 181-190.

Banchroft, J.D.; Stevens, A. and Turner, D.R. (1996). Theory and Bractes of Histological Techniques. Fourth Ed. Churchil Livingstone, New York, London, San Francisco, Tokyo. P.292.

Finney, D. J. (1964). Stastical Method in Biological Assay. 2nd Edition, Charless Griffin and Co., LTd., London, England. P. 206.

Gangadevi, V. \& Muthumary, J. (2007). Preliminary studies on cytotoxic effect of fungal taxol on cancer cell lines. African Journal of biotechnology, 6: 1382-1386.

Globocan (2008). Cancer Fact Sheet. Breast Cancer Incidence and Mortality Worldwide in 2008.

Hussein, S.A. and Azab, M.E. (1997). Effect of insulin treatment on some metabolic changes on experimentally induced tumor in female mice. The Egyptian J. Biochemistry, 15: $61-80$. 
Hussein, S.A. (2003). Clinical biochemistry interpretation and applications. First Edition (Text Book).

Lampe, V. and Milobedzka, J. (1913). Studien uber Curcumin. Ber. Deut. Chem. Ges., 46:22357.

Murray, Charles. (1984). Losing Ground: American Social Policy, 1950-1980. New York: Basic Box.

NCI (1996): Clinical development plan: Curcumin. J. Cell. Biochem., 26S: 72-85.

Pia-Foschini, M., Reis-Filho, J.S. and Eusebi, V. (2003). Salivary gland-like tumours of the breast: surgical and molecular pathology. Journal of Clinical Pathology, vol. 56, no. 7, pp. 497-506.

Rafei, I.; Fawzeya, M.A. and Mohammed, B. (1993). Possible renal dysfunction effect of nigella sativa seeds in rabbits. J. Biochem. Sci. Therapeutic, 9: 19-25.

Ramachandran, C.; Fonseca, H.B.; Jhabvala, P.; Escalon, E.A. and Melnick S.J. (2002). Curcumin inhibits telomerase activity through human telomerase reverse transcriptase in MCF-7 breast cancer cell line. Cancer Lett, 184: 1-6.

Ravi, H.; Jun, D.; Jeanne, E.; Catherine, M. and Dev, M. (2011). Detection of Apoptosis Using the BD Annexin V FITC Assay on the BD FACSVerse ${ }^{\mathrm{TM}}$ System. BD Biosciences; Application Note.

Ravichandran, R. (2013). Studies on dissolution behaviour of nanoparticulated curcumin formulation. Adv Nano-part, 2:51-59.
Saminathan, M.; Rai, R.B.; Dhama, K.; Ranganath, G.J.; Murugesan, V.; Kannan, K.; Pavulraj, S.; Gopalakrishnan, A. and Suresh, C. (2014). Histopathology and Immunohistochemical Expression of $\mathrm{N}$ Methyl-N-Nitrosourea (NMU) Induced Mammary Tumors in Sprague-Dawley Rats. Asian Journal of Animal and Veterinary Advances, 9: 621-640.

Sharma, R.; Geschar, A. and Steward, W. (2005). Curcumin the story so far. Eur J Cancer, 49:1955-1968.

Vermes, I.; Haanen, C.; Steffens-Nakken, H. and Reutelingsperger, C.P. (1995). A novel assay for apoptosis. Flow cytometric detection of phosphatidylserine expression on early apoptotic cells using fluorescein labelled Annexin V. J Immunol Methods, 184:39-51.

World Cancer Report (2014). World Health Organization. Chapter 5.2. ISBN 92-8320429-8.

Wilken, R.; Veena, M.S.; Wang, M.B. and Srivatsan, E.S. (2011). Curcumin: A review of anti-cancer properties and therapeutic activity in head and neck squamous cell carcinoma. Molecular Cancer, 10: 12.

Young, D.S. (1990). Effects of Drugs on Clinical Laboratory Tests. Third Edition. 3: 6-12.

Yousef, M.I.; El-Demerdash, F.M. and Radwan, F.M. (2008). Sodium arsenite induced biochemical perturbations in rat: Ameliorating effect of curcumin. Food Chem. Toxicol., 46: 3506-3511. 